\title{
Polymorphism in Regulatory T-cell (Treg)-Related Genes Is Associated with Unexplained Recurrent Pregnancy Loss
}

\author{
Fadel A. Sharif*, Mohammed J. Ashour, Naim T. Badawi, Shadi F. Al-Ashi \\ Department of Medical Laboratory Sciences, Islamic University of Gaza, Gaza, Palestine \\ Email address: \\ fsharif@iugaza.edu.ps (F. A. Sharif), Fadelsharif@gmail.com (F. A. Sharif)) \\ ${ }^{*}$ Corresponding author

\section{To cite this article:} \\ Fadel A. Sharif, Mohammed J. Ashour, Naim T. Badawi, Shadi F. Al-Ashi. Polymorphism in Regulatory T-cell (Treg)-Related Genes Is \\ Associated with Unexplained Recurrent Pregnancy Loss. American Journal of Clinical and Experimental Medicine. \\ Vol. 4, No. 3, 2016, pp. 63-67. doi: 10.11648/j.ajcem.20160403.15
}

Received: April 21, 2016; Accepted: April 29, 2016; Published: May 11, 2016

\begin{abstract}
In the absence of confirmed causes for around 50\% of recurrent pregnancy loss (RPL) cases this study was conducted in order to investigate the association between single nucleotide polymorphism (SNP) in regulatory T-cell related STAT3 (rs4796793 C/G), FOXP3 (rs3761548 A/C), LIF (rs3753082 T/C), NKG7 (rs71358833 A/G) and CCR5 (rs34418657 $\mathrm{G} / \mathrm{T}$ ) genes and unexplained RPL in a group of Palestinian women residing in Gaza strip. A retrospective case-control study was carried out during the period (August 2015 to March 2016). A total of 200 females, 100 RPL patients and 100 control women without previous history of RPL, aged 20-35 years were included in the study. STAT3 (rs4796793 C/G), FOXP3 (rs3761548 A/C), LIF (rs375082 T/C), NKG7 (rs71358833 A/G) and CCR5 (rs34418657 G/T) polymorphisms were tested by PCR-RFLP. Statistically significant difference existed between RPL cases and controls in terms of the genotypic distribution of the tested polymorphisms. STAT3 CC, FOXP3 AA, LIF CC, NKG7 AA and CCR5 GG genotypes were significantly higher in the RPL group. The tested polymorphisms shape the first elements of immune tolerance-related risk SNPs panel for RPL in the investigated population and may lead to improved therapeutic approaches.
\end{abstract}

Keywords: Regulatory T-cells, STAT3, FOXP3, LIF, NKG7, CCR5, Polymorphism, Recurrent Pregnancy Loss

\section{Introduction}

Recurrent pregnancy loss (RPL) is currently defined as two or more consecutive pregnancy losses before the 20th week of gestation. RPL occurs in about $2 \%$ of women at reproductive age [1]. Known causes of RPL include, anatomic (15\%), infectious (1\%-2\%), hormonal (20\%), immunological $(20 \%)$, and genetic $(2 \%-5 \%)$ have been identified. A significant number of cases (around 40\%-50\%) however, do not have known causes, and these cases are called unexplained recurrent pregnancy losses [2].

In the face of unknown etiological factor(s), breached immune tolerance is proposed as a potential mechanism underlying unexplained RPL [3]. This reportedly includes autoimmune abnormalities (e.g., positive anti-phospholipid, anti-nuclear and anti-microsomal antibodies), increased cellmediated immunity and altered regulatory T-cell level and/or suppressive capacity [4,5]. Additionally, various cytokines have been implicated in the maintenance of pregnancy through modulating the maternal immune system [6, 7].

Regulatory T-cells (Tregs), in particular, play an essential role in induction of maternal tolerance and prevention of fetal rejection by the maternal immune system. Growing evidence suggests that women with unexplained RPL had remarkably reduced levels and/or dysregulated Tregs in peripheral blood as well as in deciduas. This led some authors to suggest that Tregs may serve as a superior marker for predicting adverse pregnancy outcome [4-10].

FOXP3 (transcription factor forkhead box p3) is a member of the forkhead winged-helix transcription-factor family. FOXP3 is located on chromosome $\mathrm{X}$ (Xp11. 23) and is expressed primarily in Tregs. Foxp3 is considered the master regulator and it is lineage specific for Tregs. The reduction of Tregs level in unexplained RPL patients has been linked to decreased expression of FOXP3 [9, 11, 12].

CCR5 (chemokine receptor 5) gene product is considered the functional marker for Tregs and has been shown to be 
important for recruitment of Tregs, through CCL4, to the gravid uterus. CCR5 is situated on chromosome 3 ( $3 \mathrm{p} 21.31)$ and its product has been shown to be essential for the suppressive activity of Tregs and lack of CCR5 leads to an impairment of maternal-fetal tolerance [13].

STAT3 (signal transducer and activator of transcription 3) gene is located on chromosome 17 (17q21.2). Stat3 is a transcription factor that acts in the molecular pathway required for FOXP3 expression and has a direct role in Treg phenotype and function maintenance [14].

LIF (Leukemia inhibitory factor) whose gene is on chromosome $22(22 \mathrm{q} 12.2)$ is a cytokine produced by maternal T-cells (including Tregs) and has a direct role in the specific regulation of adaptive immune tolerance. In human pregnancy, LIF is thought to create a tolerogenic microenvironment, associated with Tregs lineage development and maintenance, suitable for embryo implantation and establishment of pregnancy [15].

NKG7 (Natural killer cell granule protein 7), on chromosome 19q13.41, codes for a cell-surface protein and is predominantly transcribed, under the control of Foxp3, in activated Tregs [16]. This protein is deemed important for the establishment of immune tolerance [17].

Genes polymorphisms related to level and/or suppressive capacity of Tregs, and thus immune tolerance, may predispose to RPL. This study was designed in order to test whether STAT3 (rs4796793 C/G), FOXP3 (rs3761548 A/C), LIF (rs3753082 T/C), NKG7 (rs71358833 A/G) and CCR5 (rs34418657 G/T) polymorphisms are associated with RPL in Palestinian women.

\section{Methods}

\subsection{Study Population}

The study was conducted on 100 Palestinian women, 1835 years old, who had at least two RPLs $\leq 20$ weeks of gestation. Age and ethnicity matched 100 women with at least two live births and without a previous history of abortion or pregnancy-associated complications served as the control group. The RPL women were free from identifiable causes of miscarriage including chromosomal, anatomic, endocrine and autoimmune causes.

\subsection{Ethical Considerations}

Informed consent was obtained from all participants.

\subsection{SNP Genotyping}

The DNA was isolated from whole blood samples using Wizard DNA extraction kit (Promega, USA) as described by the manufacturer. The isolated DNA was stored at $-20^{\circ} \mathrm{C}$ until analysis of genes polymorphisms.

PCR fragments encompassing the SNP were generated using specifically designed primers. The PCR primers (shown in Table 1) were generated by using primer3 software (http://primer3.ut.ee/) based on the genomic sequence of each gene. The sequence of each SNP was retrieved from NCBISNP database (http://www.ncbi.nlm.nih.gov/snp/). Then restriction enzymes (Table 1) required for the PCR-RFLP identification of each SNP were selected from new England Biolabs enzyme cutter software (http://nc2.neb.com (NEBcutter2/).

The PCR reactions were run in a total volume of $20 \mu \mathrm{L}$ containing: $10 \mu \mathrm{LTaq}$ PCR Master mix (Promega), $2 \mu \mathrm{L}$ (10 pmol) of primers, $4 \mu \mathrm{L}$ nuclease-free water and $2 \mu \mathrm{L}$ (40ng) of genomic DNA. Thermal cycling program consisted of a 4min denaturation at $95^{\circ} \mathrm{C}$ followed by, 35 cycles of $\left(95^{\circ} \mathrm{C}\right.$ for $30 \mathrm{~s}$ and $58^{\circ} \mathrm{C}$ for $30 \mathrm{~s}$ and $72^{\circ} \mathrm{C}$ for $30 \mathrm{~s}$ ) with a final extension at $72^{\circ} \mathrm{C}$ for $5 \mathrm{~min}$.

Ten $\mu \mathrm{L}$ aliquots of PCR products were digested with the designated restriction enzymes (New England Biolabs, UK) as recommended by the manufacturer and the digestion fragments were separated on ethidium bromide-stained $2 \%$ agarose gels. SNPs were genotyped according to the size of the fragments produced for each allele (Table 1).

\subsection{Statistical Analysis}

The genotype frequency difference between RPL patients and controls was tested by calculating the odds ratio (OR) at $95 \%$ confidence intervals $(\mathrm{CI}) . \mathrm{P}$ values $\leq 0.05$ were considered significant.

Table 1. Primers and restriction enzymes used for PCR-RFLP genotyping of the polymorphisms

\begin{tabular}{|c|c|c|c|}
\hline SNP & Enzyme & Primers5'-3' & \multirow{8}{*}{$\begin{array}{l}\text { Product size and interpretation } \\
383 \text { bp } \\
\text { T-allele: } 104+279 \text { bp } \\
\text { G-allele: uncut } \\
488 \text { bp } \\
\text { C-allele: } 124+364 \text { bp } \\
\text { T-allele: uncut } \\
227 \text { bp } \\
\text { G-allele: } 135+92 \text { bp } \\
\text { A- allele: uncut } \\
244 \text { bp } \\
\text { T-allele: } 138+106 \text { bp } \\
\text { G-allele: uncut } \\
487 \text { bp } \\
\text { C-allele: } 329+158 \text { bp } \\
\text { A-allele: } 487 \mathrm{bp}\end{array}$} \\
\hline & & F: CCCCATCTCCGCCTATAGTC & \\
\hline STAT3 rs4796793 & MwoI & R: ATGTGTTACTGGTGGGGAGG & \\
\hline & & F: AGGGGCAGGTTGCTAAGTCAG & \\
\hline rs3753082 & StuI & R: CCCCATTCTCTCAGATCCGA & \\
\hline$N K G 7$ rs71358833 & HgaI & $\begin{array}{l}\text { F: ATGAGTTCAGTGGCATCCCT } \\
\text { R: TTTCCTGGGCCTTCTACCTG }\end{array}$ & \\
\hline CCR5 rs34418657 & BbsI & $\begin{array}{l}\text { F: CCTTCTGGGCTCACTATGCT } \\
\text { R: ATGATTCCTGGGAGAGACGC }\end{array}$ & \\
\hline FOXP3 rs3761548 & PstI & $\begin{array}{l}\text { F: GCCCTTGTCTACTCCACGCCTCT } \\
\text { R: CAGCCTTCGCCAATACAGAGCC }\end{array}$ & \\
\hline
\end{tabular}




\section{Results}

Genotypic distribution of the investigated polymorphisms in RPL subjects and controls.
The genotypic frequencies of the study population are shown in (Table 2). Statistical analyses revealed that the five tested polymorphisms showed statistically significant difference between RPL cases and controls.

Table 2. Genotype frequencies of the investigated polymorphisms in controls and RPL patients.

\begin{tabular}{|c|c|c|c|c|c|}
\hline SNPs & Genotype & RPL & Controls \% & $P$ value & OR $(95 \%$ CI $)$ \\
\hline \multirow{3}{*}{ STAT3 rs4796793 } & $\mathrm{CC}$ & 57 & 41 & \multirow{3}{*}{$0.024 *$} & \multirow{3}{*}{$1.9(1.09-3.34)$} \\
\hline & $\mathrm{CG}$ & 38 & 49 & & \\
\hline & GG & 5 & 10 & & \\
\hline \multirow{3}{*}{$\begin{array}{l}L I F \\
\text { rs3753082 }\end{array}$} & GG & 55 & 28 & \multirow{3}{*}{$0.0001 * *$} & \multirow{3}{*}{$3.14(1.75-5.66)$} \\
\hline & GT & 37 & 61 & & \\
\hline & TT & 8 & 11 & & \\
\hline \multirow{2}{*}{$N K G 7$ rs71358833 } & $\mathrm{AA}$ & 70 & 44 & \multirow{2}{*}{$0.0002 * *$} & \multirow{2}{*}{$2.97(1.66-5.31)$} \\
\hline & GG & 0 & 0 & & \\
\hline \multirow{3}{*}{ CCR5 rs34418657 } & GG & 58 & 35 & \multirow{3}{*}{$0.001 * *$} & \multirow{3}{*}{$2.56(1.45-4.54)$} \\
\hline & GT & 42 & 65 & & \\
\hline & TT & 0 & 0 & & \\
\hline \multirow{3}{*}{ FOXP3 rs3761548 } & $\mathrm{C} / \mathrm{C}$ & 33 & 44 & \multirow{3}{*}{$0.011 * *$} & \multirow{3}{*}{$2.51(1.23-5.11)$} \\
\hline & $\mathrm{C} / \mathrm{A}$ & 37 & 42 & & \\
\hline & $\mathrm{A} / \mathrm{A}$ & 30 & 14 & & \\
\hline
\end{tabular}

$* P$ value $\leq 0.05$ is considered statistically significant.

** Remain significant after Bonferroni's adjustment.

\section{Discussion}

Successful implantation and maintenance of pregnancy relies on the immune tolerance imposed by the mother against her allogeneic fetus. This immune tolerance, in turn, depends on the integration of numerous mechanisms promoted by different cells present in the decidua. Interindividual genetic variation- SNPs in particular- affect the level and function of immune tolerance-related proteins and may modify the risk for unexplained RPL, graft rejection and many immune diseases.

Results of the present work showed that particular SNPs in STAT3, LIF, NKG7, CCR5 and FOXP3 Treg/immune tolerance related genes are significantly associated with RPL. Indeed, studies have shown that polymorphisms in those genes are associated with various inflammatory and autoimmune diseases, such as rheumatoid arthritis, multiple sclerosis and SLE, that may also predispose to RPL $[3,8,9$, 18-21]. However, very limited studies, and for $N K G 7$ no previous studies, have investigated the direct relation between those five polymorphisms and unexplained RPL.

STAT3 rs4796793 $(-1697 \mathrm{C}>\mathrm{G})$ is located in the promoter region of the gene and has been shown to strongly affect the transcription rate of the gene. This SNP could generate a transcription factor binding site for FOXD1 that represses transcription $[22,23]$. It is possible that transcription of the STAT3 G-allele at rs4796793 might be down-regulated by FOXD1. This in turn, may explain the association between the GG genotype and RPL in our study population. This same SNP has been shown by Xu et al. (2014) to be associated with Crohn's disease [24]. It is worth mentioning here that, other STAT3 SNPs (e.g., rs1053004) have been shown to be linked with unexplained RPL [25].

The leukemia inhibitory factor is essential for creating the immune tolerance required for embryo implantation and establishment of pregnancy. The investigated SNP rs3753082 ( $\mathrm{T}$ to $\mathrm{C}$ transition) is located in the $3^{\prime}$ untranslated region of the $L I F$ gene. The $\mathrm{C}$-allele of this polymorphism is suggested to reduce mRNA stability and may have an effect on the amount of secreted LIF [26] and hence an impact on the tolerogenic microenvironment at the feto-maternal interface.

This is the first study investigating $N K G 7$ gene polymorphism in RPL. The cell surface protein encoded by this gene is expressed on Tregs and other immune system cells and is a suggested biomarker for immune tolerance. $N K G 7$ up-regulation has been linked to allograft rejection [27] implicating its role in establishment of immune tolerance. SNP rs71358833 is located in the promoter region of $N K G 7$ and the association between AA genotype and RPL may be due to increased expression of $N K G 7$ in RPL cases.

The chemokine receptor CCR5 is necessary for maternalfetal tolerance through influencing recruitment and suppressive function of Tregs [13]. The tested rs34418657 affects the structure and function of CCR5 [28] and thus explains its association with RPL. This SNP changes amino acid 131 from valine to phenylalanine (V131F) in the CCR5 polypeptide.

Foxp3 is a key regulator for development and function of the immunosuppressive Treg cells and it plays a critical role in induction of fetal-maternal tolerance [12] and is considered along with $N K G 7$ as tolerance biomarker. The association between FOXP3 gene polymorphisms and adverse pregnancy outcomes could be due to abnormal transcription of FOXP3. In fact, Shen et al., (2010) in their study on psoriasis patients have shown that FOXP3 
rs3761548 A/A genotype causes loss of bindings to the E47 and c-Myb transcription factors, leading to defective transcription of FOXP3 gene [29].

In conclusion, results of the present study revealed that the five investigated polymorphisms proved to be significantly associated with RPL and could represent the first elements of Treg/immune tolerance-related risk SNPs panel for predicting RPL. The study findings may also lead to improved therapeutic interventions. We believe that the five tested SNPs modify the RPL risk in an independent manner, as they are located on entirely different chromosomes. Future work should be directed towards testing additional Tregs/immune tolerance related gene polymorphisms in RPL patients.

\section{Declarations}

Funding: This work was supported by the Scientific Research Council [Scientific Research Grant 2014-2015], Ministry of Education and Higher Education, State of Palestine.

Conflict of interest: The authors hereby declare that no competing interests exist.

Ethical approval: Obtained from the local Helsinki ethics committee.

\section{References}

[1] Branch DW, Gibson M, Silver RM. Recurrent miscarriage. New England Journal of Medicine 2010; 363(18):1740-1747.

[2] Rull K, Nagirnaja L, Laan M. Genetics of recurrent miscarriage: challenges, current knowledge, future directions. Frontiers in genetics. 2012; 3:34.

[3] Jenkins C, Roberts J, Wilson R, MacLean MA, Shilito J, Walker JJ. Evidence of a T(H) 1 type response associated with recurrent miscarriage. Fertility and sterility. 2000; 73(6):12061208.

[4] Zenclussen AC, Gerlof K, Zenclussen ML, et al. Regulatory T cells induce a privileged tolerant microenvironment at the fetal - maternal interface. European journal of immunology. 2006; 36(1):82-94

[5] Saito S, Nakashima A, Shima T, Ito M. Th1/Th2/Th17 and Regulatory Treg Cell Paradigm in Pregnancy. American journal of reproductive immunology 2010; 63(6):601-610.

[6] Coffer PJ, Burgering BM. Forkhead-box transcription factors and their role in the immune system. Nature Reviews Immunology. 2004; 4(11):889-899.

[7] Perricone C, de Carolis C, Perricone R. Pregnancy and autoimmunity: a common problem. Best Pract Res Clin Rheumatol. 2012; 26(1):47-60.

[8] Yang H, Qiu L, Chen G, Ye Z, Lü C, Lin Q. Proportional change of $\mathrm{CD} 4+\mathrm{CD} 25+$ regulatory $\mathrm{T}$ cells in decidua and peripheral blood in unexplained recurrent spontaneous abortion patients Fertility and sterility. 2008; 89(3):656-661.

[9] Mei S, Tan J, Chen H, Chen Y, Zhang J. Changes of
$\mathrm{CD} 4+\mathrm{CD} 25$ high regulatory T cells and FOXP3 expression in unexplained recurrent spontaneous abortion patients. Fertility and sterility. 2010; 94(6):2244-2247.

[10] Jiang G, Qiu L, Lin Q. Regulative effects of regulatory T cells on dendric cells in peripheral blood and deciduas from unexplained recurrent spontaneous abortion patients. Zhonghua fu chan ke za zhi. 2009; 44(4):257.

[11] Lin Y, Lee J, Wu AS, et al. Association of single-nucleotide polymorphisms in FOXP3 gene with systemic lupus erythematosus susceptibility: a case-control study. Lupus. 2011; 20(2):137-143.

[12] Coffer PJ, Burgering BM. Forkhead-box transcription factors and their role in the immune system. Nature Reviews Immunology. 2004; 4(11):889-899.

[13] Andersen M, Andersen KG, Welch KA, Betz AG. Alloantigen-enhanced accumulation of CCR5+ 'effector' regulatory T cells in the gravid uterus. Proc Natl Acad Sci U S A. $2007 ; 104(2): 594-599$.

[14] Pallandre JR, Brillard E, Créhange G, Radlovic A, RemyMartin JP, Saas P, Rohrlich PS, Pivot X, Ling X, Tiberghien $\mathrm{P}$, Borg C. Role of STAT3 in CD4+CD25+FOXP3+ regulatory lymphocyte generation: implications in graftversus-host disease and antitumor immunity. J Immunol. 2007; 179(11):7593-604.

[15] Metcalfe SM. LIF in the regulation of T-cell fate and as a potential therapeutic. Genes and Immunity $2011 ; 12: 157-168$

[16] Sugimoto N, Oida T, Hirota K, Nakamura K, Nomura T, Uchiyama T, Sakaguchi S. Foxp3-dependent and -independent molecules specific for CD251CD41 natural regulatory T cells revealed by DNA microarray analysis. International Immunology 2006; 18(8): 1197-1209.

[17] Pidala J, Bloom GC, Eschrich S, Sarwal M, Enkemann S, Betts BC. Tolerance Associated Gene Expression following Allogeneic Hematopoietic Cell Transplantation. PLoS ONE 2015; 10(3): e0117001.

[18] Eastell T, Hinks A, Thomson W. SNPs in the FOXP3 gene region show no association with Juvenile Idiopathic Arthritis in a UK Caucasian population. Rheumatology. 2007:46(8):1263-1265.

[19] Tower C, Crocker I, Chirico D, Baker P, Bruce I. SLE and pregnancy: the potential role for regulatory $\mathrm{T}$ cells. Nature Reviews Rheumatology. 2011; 7(2):124-128.

[20] Qiu F, Song L, Yang N, Li X. Glucocorticoid downregulates expression of IL-12 family cytokines in systemic lupus erythematosus patients. Lupus. 2013; 22(10):1011-1016.

[21] Chen X, Gan T, Liao Z, Chen S, Xiao J. Foxp3 (-/ATT) Polymorphism Contributes to the Susceptibility of Preeclampsia. PloS one 2013; 8(4):e59696.

[22] Wu Z, You Z, Zhang C, et al. Association between functional polymorphisms of Foxp3 gene and the occurrence of unexplained recurrent spontaneous abortion in a Chinese Han population. Clinical and Developmental Immunology. 2012; 2012.

[23] Raghupathy R, Makhseed M, Azizieh F, Omu A, Gupta M, Farhat R. Cytokine production by maternal lymphocytes during normal human pregnancy and in unexplained recurrent spontaneous abortion. Human Reproduction. 2000; 15(3):713-718. 
[24] Wang Z, Xu B, Zhang H, Fan R, Zhou J, Zhong J. Association between STAT3 gene Polymorphisms and Crohn's disease susceptibility: a case-control study in a Chinese Han population. Diagnostic Pathology 2014, 9:104-109.

[25] Finan RR, Mustafa FE, Al-Zaman, Madan S, Issa AA, Almawi WY. STAT3 polymorphisms linked with idiopathic recurrent miscarriages. Am J Reprod Immunol. 2010; 63(1):22-7.

[26] Ishida R, Ezura Y, Iwasaki H, et al. Linkage disequilibrium and haplotype analysis among four novel single-nucleotide polymorphisms in the human leukemia inhibitory factor (LIF) gene. J Hum Genet. 2001; 46(10):557-559.

[27] Ashokkumar C, Ningappa M, Ranganathan S, Higgs BW, Sun
Q, et al. Increased Expression of Peripheral Blood Leukocyte Genes Implicate CD14+ Tissue Macrophages in Cellular Intestine Allograft Rejection. The American Journal of Pathology 2011; 179(4): 1929-1938.

[28] Structure-Function Studies on Non-synonymous SNPsof Chemokine Receptor Gene Implicated in Cardiovascular Disease: A Computational Approach. A. Sai Ramesh, Rao Sethumadhavan, Padma Thiagarajan. Protein J. 2013; 32:657665

[29] Shen Z., Chen L., Hao F., Wang G., Liu Y. Intron-1 rs3761548 is related to the defective transcription of Foxp3 in psoriasis through abrogating E47/c-Myb binding. J. Cell. Mol. Med. $2010 ; 14: 226-241$. 